\title{
Matemática para a primeira série em livros didáticos russos
}

\section{Circe Mary Silva da Silva}

Universidade Federal de Pelotas

cmdynnikov@gmail.com

\begin{abstract}
Resumo
O presente texto visa responder a seguinte questão investigativa: quais conteúdos e metodologia são propostos para o ensino da matemática para a primeira série do ensino fundamental no livro didático das autoras Moro, Volkova, Stepanova e Bantova? O material escolhido para a análise foi uma coleção de livros das autoras intitulada Matemática, de 2011, e para um aprofundamento desta coleção, foi analisada a obra, Matemática - recomendações metodológicas para a primeira série, de Bankova et al (2014), além do livro de Bakhtina (2012), guia para a utilização da referida coleção, no primeiro ano. A análise qualitativa centrou-se nas categorias: numeração, problemas lógicos, operações de adição e subtração, formulação de problemas, introdução ao pensamento algébrico, geometria. Além da análise documental, realizou-se entrevista on-line com as autoras da obra Matemática. Constatou-se a presença de um ensino desenvolvimental na proposta metodológica de matemática das autoras.
\end{abstract}

Palavras-chave: Ensino de Matemática. Livro Didático. Ensino Desenvolvimental. Rússia

\section{Mathematic for the first series in russian textbooks}

\begin{abstract}
This article aims to answer the following research question: what contents and methodology are proposed for the teaching of mathematics for the first grade of elementary school in the textbook of the authors, Moro, Volkova, Stepanova and Bantova? The material chosen for the analysis was a collection of books by the authors entitled Mathematics, 2011, and for a further study of this collection, the work, Mathematics - methodological recommendations for the first grade, by Bankova et al (2014), in addition to the book by Bakhtina (2012), which guides the use of the collection in the first year. The qualitative analysis focused on the categories: numbering, logical problems; geometry; addition and subtraction operations; problems solving; introduction to algebraic thinking; geometry; In addition to the documentary analysis, an online interview was conducted with the authors of the work Mathematics. It was verified, through the interpretation of texts and referendum of the authors themselves, the presence of a developmental teaching in the methodological proposal of mathematics of the authors.
\end{abstract}

Keywords: Mathematics Teaching. Textbook. Developmental Teaching. Russia. 


\section{Introdução}

A investigação sobre livros didáticos tem crescido nos últimos anos em vários países (CHOPPIN, 2004). No Brasil, pouco se conhece sobre os livros didáticos de matemática utilizados no ensino fundamental da Federação Russa, embora tenham surgido trabalhos relevantes sobre V. V. Davydov e o ensino desenvolvimental como os Damazio (2006), Rosa (2012), Libâneo (2013), entre outros. Ao apresentarmos um estudo sobre livros didáticos russos das autoras Moro et al não pretendemos uma comparação direta com os livros brasileiros, mas sim considerar o outro para compreender a si mesmo, pois conforme Ciavatta (2009, p. 129): "a questão do outro e do reconhecimento da alteridade é a base do conhecimento da identidade de si mesmo e da distinção em relação aos demais seres".

Atualmente, na Rússia, o ensino fundamental compreende 3 etapas: a primeira começa entre os seis e sete anos de idade e tem duração de 4 anos (ensino inicial); a segunda tem 5 anos de duração; a terceira tem 2 anos. Os livros didáticos são escritos para cada série. Até os anos 1990, existiu um único programa estatal de ensino de matemática. A partir dos anos 1990, foi permitida a variação de métodos de ensino. Surgiram, então, vários grupos de autores - entre os quais aqueles adeptos do ensino desenvolvimental - com seus livros didáticos e programas próprios, mantendo, porém, as diretrizes básicas do governo. Estas diretrizes estão expressas na proposta conhecida no país com a sigla UDD - ações universais de ensino, que são metas para o ensino na Rússia. Elas objetivam desenvolver a capacidade de aprender, isto é, a capacidade do ser humano de se aperfeiçoar mediante a vivência de novas experiências sociais. São os seguintes os tipos de ações: ações personalizadas, ações regulativas, ações de aprendizagem e ações comunicativas. As recomendações metodológicas apresentam os principais objetivos da educação matemática para a escola inicial: garantir o desenvolvimento intelectual da criança (conhecimento matemático, pensamento, imaginação espacial e fala); formar ações universais de ensino com base de conteúdo matemático; garantir que os alunos entendam a universalidade de abordagem matemática do conhecimento das leis ambientais e formação de capacidade de usar (ler e construir) modelos visuais; refletir a correspondência quantitativa e espacial entre objetos; formar e desenvolver interesse pelo trabalho mental, desenvolver a capacidade artística, motivar para o ensino, formar a capacidade de aplicar os conhecimentos adquiridos para obtenção de conhecimentos novos, desenvolver a capacidade de estudar (BANKOVA; BELTIUKOVA; VOLKOVA; STEPANOVA; IGUCHEVA, 2014, p. 2).

Considerando o aumento significativo da quantidade de livros didáticos, o Ministério da Educação e Ciência da Federação da Rússia, periodicamente vem selecionando esse material para apoiar a sua publicação. Na lista para o biênio 2014 - 2015, foram recomendados, pelo Conselho 
científico-metodológico, aqueles livros com pareceres positivos de especialistas na parte científica, pedagógica e social. Entre os recomendados ${ }^{1}$, encontra-se a coleção Matemática [Математика], para as quatro primeiras séries do ensino fundamental ${ }^{2}$, composta de 8 livros (dois para cada série) e 8 Cadernos de Exercícios (dois para cada ano) ${ }^{3}$ e 4 cadernos de controle escritos pelos autores: M. I. Moro, C. I. Volkova, S. V. Stepanova e S. I. Volkova (2011).

Embora existam vários grupos de autores que contaram com apoio estatal para publicação de seu material didático, para análise foi escolhida a coleção liderada por Moro, pois ela pode ser considerada difundida uma vez que, em 2008, o livro para $1^{\circ}$ ano, $1^{\mathrm{a}}$ parte, estava em sua oitava edição. Neste trabalho, analisamos a edição de 2011, tendo como propósito, principalmente, identificar a metodologia proposta na coleção. Analisamos, também, o livro Matemática recomendações metodológicas para a primeira série: uma ajuda para professores das instituições gerais de ensino [математника: методические рекомендции: Пособие для учителей общеобразовательных организаций], das autoras Bankova, Beltiukova, Volkova, Stepanova e Igucheva, de 2014, com orientações metodológicas para suporte ao livro didático de Moro et al. Além disso, o livro de S.V. Bakhtina (2012) - Para o desenvolvimento de cada aula de matemática do primeiro ano dos livros de Moro - foi estudado, pois ele serve para compreendermos como o professor deve colocar em prática um ensino baseado em tais livros didáticos.

O presente texto visa responder a seguinte questão investigativa: quais conteúdos e metodologia são propostos para o ensino da matemática para a primeira série do ensino fundamental no livro didático das autoras Moro, Volkova, Stepanova e Bantova e há nele evidências de uma prática de ensino desenvolvimental?

Apresentamos, a seguir, uma breve contextualização histórica que pretende situar o desenvolvimento do ensino desenvolvimental na Rússia.

\section{Contexto Histórico}

Na antiga União Soviética, na década de 1950, surgiram experiências de ensino baseadas em teorias psicológicas, as quais foram lideradas por L. V. Zankov (1901-1977), D. B. Elkonin (19041984) e V. V. Davydov (1930-1998). Entre esses, Zankov e Elkonin estudaram diretamente com Vygotsky ${ }^{4}$. Paralelamente, no final da década de 1950, coordenadas por Elkonin e Davydov,

\footnotetext{
${ }^{1}$ Por determinação de 31 de março de 2014, do Ministério de Educação e Ciência da Federação da Rússia "Sobre afirmação da Lista federal dos livros didáticos recomendados para realização nos programas credenciados do ensino inicial geral, básico geral e médio geral". Disponível em < http://www.consultant.ru/document/cons_doc LAW_162928> Acesso em: 12 Maio 2014.

${ }^{2}$ Pela classificação russa, denomina-se ensino inicial.

${ }^{3}$ A edição de 2012 possui também um CD.

${ }^{4}$ Os cinco discípulos diretos mais próximos de Vygotsky foram: Aleksandr Vladimirovitch Zaporojets, ucraniano, Bojovitch, Morozova, Levina, Slavina. Nenhum deles trabalhou com ensino desenvolvimental.
} 
começaram a ser realizadas pesquisas para testar, justificar e concretizar as hipóteses de L. S. Vygotsky sobre o ensino desenvolvimental. Já no ano letivo 1959-1960, na Escola nº 91 de Moscou, foi criado um laboratório - uma classe experimental para o primeiro ano - onde começaram a ser pesquisados os problemas originais de psicologia e pedagogia, relacionados com a formação de atividade de ensino de alunos do ensino inicial.

Em 1962, juntamente com Elkonin, Davydov publicou Questões de psicologia da atividade do ensino dos alunos da escola inicial. Mas foi somente na década de 1980 que suas ideias começaram a ser implantadas e livros didáticos que as contemplassem começaram a ser produzidos.

Elkonin e Davydov identificaram um problema científico e prático de conexão entre ensino e desenvolvimento dos alunos da escola inicial. Constataram que mudanças no conteúdo e métodos de ensino tradicional dão certo efeito positivo no desenvolvimento das crianças.

Nós descobrimos que a chave para o problema do desenvolvimento da formação dos alunos da escola inicial - escreveu D. B. Elkonin: é conteúdos de ensino. Segundo ele, para que a educação na escola inicial seja desenvolvimentista, devemos nos preocupar com o seu conteúdo científico. Isto significa que as crianças aprendem o sistema de conceitos científicos e métodos para a sua obtenção ${ }^{5}$.

Para Davydov, o conceito de atividade é essencial, pois, segundo esse autor, "o sujeito interage ativamente com o objeto e, ao buscá-lo e prová-lo, encontra-o, de um modo parcial e seletivo" (DAVYDOV, 1962, p. 16). Encontra-se nessa conceituação uma relação direta entre o sujeito e o objeto, pois o ser humano ao procurar apropriar-se dos objetos e do mundo circundante realiza uma atividade a qual é mediada pela comunicação. A criança em seu aprendizado também passa por esse processo relacional que envolve sujeito e objeto por meio da atividade. Sobre o complexo conceito de atividade e seu papel no aprendizado humano, manifestaram-se outros psicólogos soviéticos como Leontiev para quem a atividade "[...] pressupõe não apenas as ações de um só indivíduo tomado isoladamente, mas também suas ações no contexto da atividade das outras pessoas, ou seja, pressupõe certa atividade conjunta" (DAVYDOV, 1962, p. 17). Leontiev assumiu a educação como uma atividade.

No seu último livro, publicado em 1996, com o apoio da escola nº 91, V. V. Davydov teceu considerações sobre o difícil processo de criação de programas específicos e métodos de ensino desenvolvimental e assinalou a necessidade de resolução de novos problemas lógico-psicológicos e didático-metodológicos, os quais exigem a organização de trabalho multidisciplinar ${ }^{6}$.

\footnotetext{
Disponivel em <http://uk.wikipedia.org/wiki/Запорожець_Олександр_Володимирович >. Acesso em: 5/08/2014.

${ }^{5}$ Disponível em<http://91.ru/wp-content/uploads/Концепция-развития-школы1.htm>. Acesso em 8 maio de 2015.

${ }^{6}$ Disponível em < http://91.ru/wp-content/uploads/Концепция-развития-школы1.htm>. Acesso em 02/08/2014.
} 
Como nossa análise restringe-se à etapa inicial de ensino (primeiro ano), apresentamos a seguir um esboço sumário das ideias de Davydov para essa fase:

Quadro 1 - Objetivo Principal na etapa de ensino inicial

Garantir o desenvolvimento psíquico substancial do aluno dentro do processo de sua formação como sujeito de diversos tipos e formas de atividade, interessado em automudança e capaz de realizá-la

\section{Tarefas}

Formação de fundamentos de pensamento teórico e consciência
Desenvolvimento da criança como sujeito de atividade educacional
Formação da personalidade através da criação do sistema de orientação de valores

\section{$\downarrow \downarrow \downarrow \downarrow$}

Conteúdo de educação desenvolvimental inicial

Componente principal - um sistema de conceitos científicos e métodos para sua obtenção

\section{Métodos de ensino}

De pesquisa e busca parcial
Formas de organização de atividade cognitiva de alunos

Atividade educacional coletiva
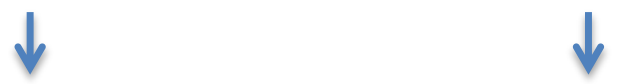

Desenvolvimento de alunos como resultado da educação especialmente organizada

Fase preparatória

- Desenvolvimento da imaginação

- Capacidade de ação coletiva considerando a posição da outra pessoa

No final do ensino inicial

- Capacidade de pensamento teórico - desenvolvimento de ações principais como componentes do pensamento: reflexão, análise, planejamento, abstração e generalização

Fonte: Elaborado pela autora baseada nos estudos realizados sobre Davydov $(1962,1982,1988)$

Especificamente em relação à matemática proposta nos livros da coleção Moro et al, procurase identificar se as atividades propostas visam à aquisição de pré-requisitos para a formação do pensamento teórico dos alunos e se estão voltadas para a aprendizagem de conceitos científicos.

\section{Características da obra de Moro}

O material didático para o primeiro ano da coleção de Moro et al compreende: dois livros didáticos (Figura 1); dois cadernos de tarefas; um caderno de controle; encartes em papelão e uma mídia. O 
conteúdo e a estrutura do livro didático centralizam termos básicos do curso inicial de matemática: número, grandeza e figura geométrica.

\section{Figura 1 - Capas dos livros do primeiro ano}
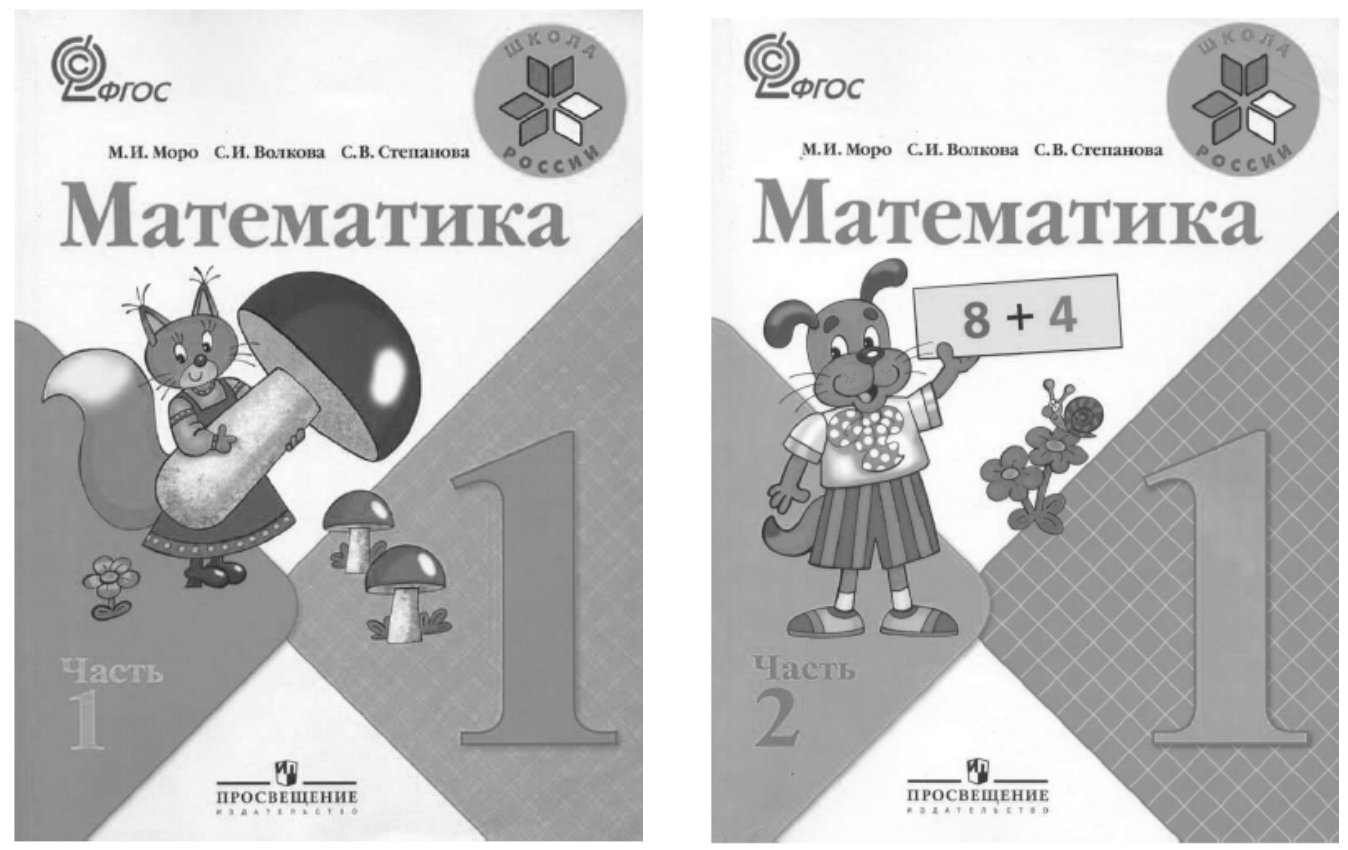

Fonte: Moro et al, v. 1 e 2, ano

Uma breve visão sobre os dois livros deixa entrever uma proposta calcada na junção da aritmética com geometria, mas já com um simbolismo preparatório para a álgebra, que será trabalhada a partir do segundo ano. O primeiro livro do primeiro ano trata apenas da numeração até 10, enquanto o segundo livro, da numeração até 20.

Os problemas para curiosos permitem já no primeiro ano: 1) estabelecer uma base para o desenvolvimento da habilidade de observar, comparar, analisar, classificar os objetos, fazer generalizações e procurar análogos, criar cadeia de pensamentos lógicos, aplicar o conhecimento nas condições alteradas, e realizar conclusões; 2) direcionar para a formação dos fundamentos de alfabetização computacional, em particular, desenvolver o pensamento algoritmo, a habilidade de compor um plano de ações e realizá-lo para a resolução do problema de ensino e, ainda, realizar o controle em cada passo.

Constatamos que, nesse nível de escolaridade, já há uma grande preocupação com a integração dos saberes, semelhante à proposta de Davydov, o que nos leva a concordar com a análise de Rosa (2012, p. 31), de que "as proposições davydovianas para o ensino do conceito de número contemplam de forma inter-relacionada as significações aritméticas, algébricas e geométricas". 
A fim de identificar se houve uma apropriação, pelas autoras da obra, da proposta de ensino desenvolvimental, utilizamos a técnica de análise de conteúdo. Formulamos as seguintes categorias: numeração, operações de adição e subtração, problemas lógicos, geometria, formulação de problemas e introdução ao pensamento algébrico.

\section{Numeração}

Segundo as orientações metodológicas, a experiência mostrou que, para o estudo dos números de 1 a 10, uma introdução simultânea de dois números abre um espaço mais amplo para comparação entre os números e para conhecimento, mais cedo, de operações com eles (BANKOVA et al., 2014). Assim, os numerais 1 e 2 são apresentados simultaneamente e com eles são realizadas operações de adição e subtração, sem uso de simbologia. O numeral 3 é apresentado e, a seguir, os símbolos de +, -, =. A partir daí, as operações de adição com esses três números passam a usar os símbolos antes mencionados.

Passo a passo, os exercícios com cálculo ficam mais sofisticados: primeiramente contar os objetos iguais (desenhos, sons, movimentos), depois diferentes (tipo de brinquedos, animais, etc). Inicialmente, o professor está formulando tarefas e convidando as crianças a inventar as próprias perguntas com as palavras "quantos" e responderem a essas perguntas. Os alunos começam a denominar os números e a mostrar os objetos correspondentes no quadro, depois calculam os objetos mentalmente, pensam sobre número e movem os olhos de um objeto para outro. Essa formulação própria de enunciados, envolvendo a capacidade de imaginação, pode ser entendida como uma das características do ensino desenvolvimental.

Algumas aulas são reservadas para fixação da matéria vista, em particular os números 2, 3, 4, 5. Além disso, está previsto o estudo do material geométrico: curva e linha reta, raio, segmento de reta, linha quebrada e segmento da linha quebrada, polígonos; são introduzidos os termos "igualdade" e "desigualdade", os símbolos >, <, =. A busca pela generalização e utilização de simbolismo algébrica desde o primeiro ano escolar é meta proposta por Davydov.

Depois são estudados os números do segundo grupo de 5, observando os segmentos da linha reta correspondentes à sequência natural: 1 - 6,1 - 7,1 - 8,1-9,1-10. Com o objetivo de ensejar a generalização dos conhecimentos, é necessário oferecer tarefas que permitam estabelecer, sobre um número dado, uma generalização. Por exemplo, o número 5 pode ser obtido assim: 4 mais 1 , ou 3 mais 2 , ou 6 menos 1 . O número 5 está composto de números 4 e 1,3 e 2 . O número 5 é 1 a mais que 4, e 1 a menos que 6 . O número 5 está na sequência de números depois do número 4 antes do número 6. Desenvolver a capacidade de generalizar e do pensamento teórico é a base do ensino 
desenvolvimental.

Para garantir a formação da ação educativa comunicativa, recomendam o trabalho em duplas, em particular nos jogos matemáticos, envolvendo a numeração.

\section{Operações de adição e subtração}

Segundo Moro et al (2011), é importante introduzir no estudo da adição e subtração as terminologias parcelas, soma, minuendo, subtraindo e diferença para operações aritméticas bem como os símbolos matemáticos de igualdade e desigualdade que são símbolos de comparação.

No livro de metodologia (2014), as autoras descrevem como é apresentada, no livro didático, a metodologia sobre a adição e subtração de números até 20 . O professor deve, já no primeiro ano, tentar fazer com que as crianças passem para formulações mais curtas, para cálculos do tipo $8+5$, na qual elas procuram um número para completar 10, (são dois de que precisa para completar 10 se já tem 8), sobram 3 (do cinco) e assim chega-se a 13.

$\mathrm{Na}$ figura 2, temos exemplos de atividades extraídas do livro que mostram as adições de $9 \mathrm{e}$ $4 ; 8$ e 4; 6 e 5; 7 e 4, todas usando o completamento de dez da primeira parcela.

Figura 2 - Operação de Adição com completamento

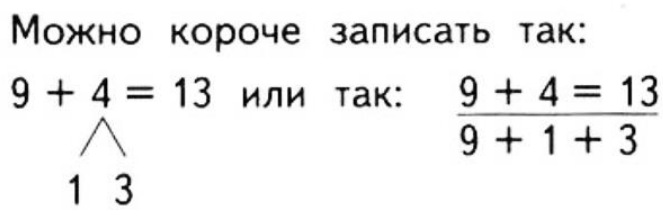

1. Вычисли с устным объяснением.

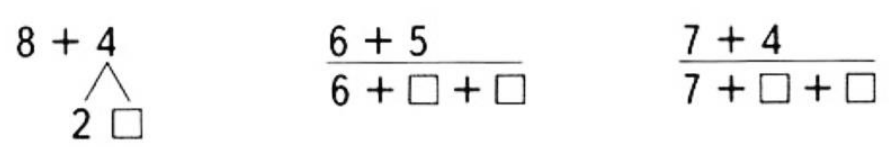

Fonte: Matemática, 2011, vol. 2, p. 64
Tradução: pode ser escrita de maneira mais curta, ou como

1. Calcule com explicações orais

O próprio enunciado da atividade sugere que o aluno elabore sua explicação na oralidade, visando a formação de um pensamento teórico e não apenas a manipulação de algoritmos de maneira mecânica. A operação de subtração segue a mesma orientação que a de adição, trabalhando com completamento de dezena.

\section{Problemas Lógicos}

Para a resolução de problemas lógicos, os alunos estabelecem uma relação razão-consequência entre objetos, montam cadeias de pensamentos lógicos, tiram conclusões, de acordo com as condições dadas. A tarefa metodológica do professor é de mediação de maneira a auxiliar na elaboração de um 
plano de resolução de problemas deste tipo: destacar e fixar a relação entre dois (ou mais) objetos, tirar conclusão e usá-la na próxima discussão na qual deve ser feita uma conclusão. Um exemplo em que o aluno usa uma simbologia de abreviações é o seguinte problema proposto: "Determine o que aconteceu antes e o que ocorreu depois. Kolobok ${ }^{7}$ encontrou o lobo, depois que encontrou o coelho, porém antes de encontrar o urso. Quem deles Kolobok encontrou em primeiro lugar e em segundo lugar?” A metodologia sugerida ao professor é a seguinte:

"O professor anota no quadro, usando apenas as primeiras letras de nomes de animais, respostas das crianças para perguntas deste tipo: - Quem Kolobok encontrou antes: Lobo ou Coelho? (Coelho.) As anotações no quadro são: C. antes do L.; L. antes do U.; C. antes do L., mas L. antes do U. - Qual conclusão é possível tirar? (O primeiro encontrado foi Coelho, o segundo, Lobo.)"(BANKOVA et al., 2014, p. 48).

A mediação proporcionada pelo professor permite a introdução de símbolos preparatórios para o desenvolvimento do pensamento algébrico.

Um outro exemplo, é o seguinte problema proposto (Figura 3)

\section{Figura 3 - Tarefa lógica dos gatos}
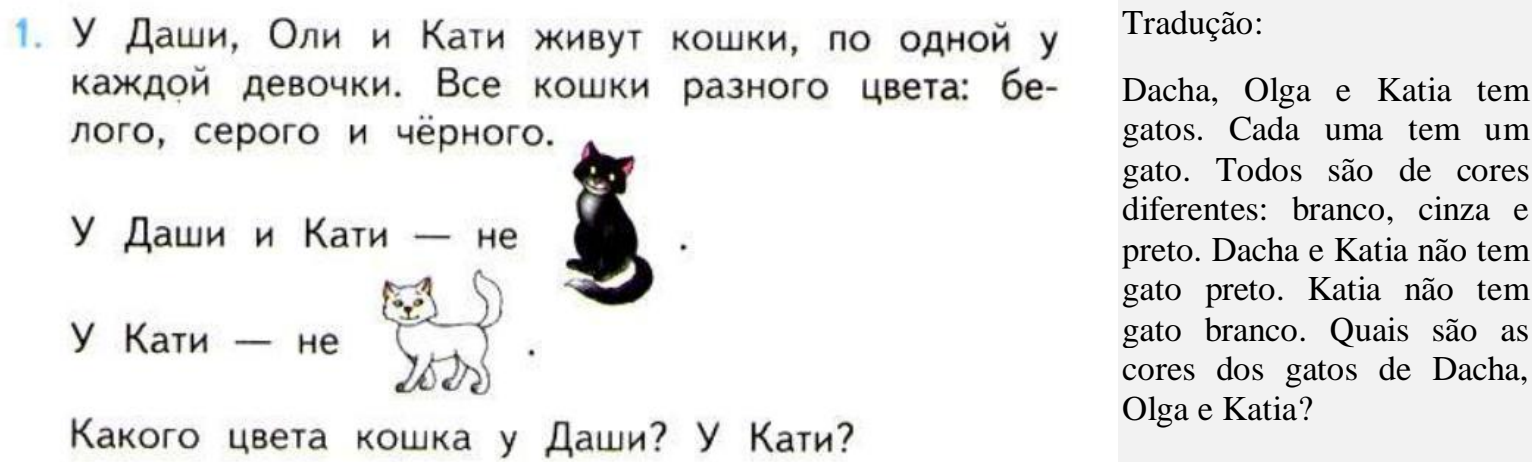
gato. Todos são de cores diferentes: branco, cinza e preto. Dacha e Katia não tem gato preto. Katia não tem gato branco. Quais são as cores dos gatos de Dacha, Olga e Katia?

Fonte: Matemática, vol.1, 2011, p. 102

O problema resolve-se sob mediação do professor (BANKOVA et al, 2014, p. 35).

- O que sabemos a respeito da cor de gatos da Dacha e Katia? (Tanto Dacha como Katia não tem gato preto). Qual conclusão pode ser feita? (O gato preto está com Olga).

- O que mais sabemos sobre a cor do gato da Katia? (O gato da Katia não é branco).

- Agora sabemos que o gato da Katia não é nem preto, nem branco, então Katia tem

... (gato na cor cinza), enquanto a Dacha tem um gato branco.

Durante a resolução de problemas deste tipo é útil criar um modelo gráfico (desenho esquemático) que interpreta as relações entre objetos. Segundo as mesmas autoras, a habilidade de ler, em grande parte, define o sucesso no estudo de matemática.

\footnotetext{
${ }^{7}$ Kolobok é um personagem da mitologia russa.
} 


\section{Geometria}

O material geométrico ocupa um grande espaço no livro didático. Ele contém material para as crianças alcançarem uma ideia sobre linhas, raio, segmento de reta, a linha quebrada e polígono. Para um estudo mais aprofundado desses termos, são oferecidas tarefas diversas, na forma divertida (problemas de construir figuras usando palitos) como, por exemplo, "Construa com 7 palitos 2 quadrados, e com 10 palitos um quadrado grande e outro pequeno" (MORO, 2011, vol. 2, p. 16).

$\mathrm{O}$ livro didático organiza-se em uma abordagem por atividades sistematizadas, refletida na estrutura de cada aula, no seu conteúdo e no ensino de matemática em geral. Devido a isso, foram criadas as condições para envolvimento ativo de cada aluno no processo de ensino (BANKOVA et al, 2014, p. 21).

Muitas atividades que estimulam a comparação de segmentos são apresentadas. Há uma simbiose de conceitos aritméticos e geométricos, os alunos são solicitados a trabalhar com grandezas, com polígonos, ângulos, vértices, com o centímetro, com a hora, o sistema monetário, com as noções de aumento e diminuição e, além de trabalharem com os números de 6 a 10, eles são apresentados ao zero.

Quando começa o ensino da escrita dos números, usam-se as palavras "ponto", "ângulo", "linha reta" etc. Por isso, estes termos também são conhecidos pelas crianças. Durante a abordagem dos números 3 e 4, o livro didático oferece exercícios sobre modelagem de triângulo e quadrado usando palitos. Aqui, geralmente, as crianças aprendem os elementos destas figuras - mostram e calculam medidas de lados, indicam ângulos e vértices.

Há uma ênfase grande na aquisição do conceito de segmento. O entendimento de segmento geralmente é introduzido de forma prática. Com a ajuda de um fio, colocado entre duas bobinas, "representam" uma linha reta, depois cortam uma parte dela com tesoura. Mostrando uma reta, segmento ou raio no quadro (ou numa folha), destacam a sua semelhança (usam uma régua) e diferença: diferentemente da linha reta, que não tem limites, o segmento tem pontos inicial e final. Para a fixação, estão previstos exercícios do tipo: desenhar uma linha reta, raio e segmento; traçar 2 linhas que se cruzam; numa reta marcar 2 ou 3 pontos e calcular os segmentos obtidos; comparar visualmente estes segmentos, colocado um embaixo de outro, ordenar pelo comprimento etc.

Segundo (BANKOVA et al, 2014, p. 57).

Com base na comparação de triângulos e quadriláteros (onde há semelhança e onde há diferença), introduz-se o conceito do polígono (Parte 1, p. 50). É importante que 
as crianças façam uma generalização correta, sem utilizar este termo apenas para polígonos que têm muitos ângulos. Entre os polígonos que as crianças estão analisando, é necessário destacar o triângulo como polígono com a menor quantidade de ângulos, vértices e lados. Resolvendo problemas (Vol. 1, p. 55) tais como "Quantos quadrados estão no desenho?", é possível lembrar todos os nomes desta figura (quadrilátero, polígono).

Figura 4 - Tarefa de geometria

\section{Сколько треугольников на чертеже? Сколько квадратов?}
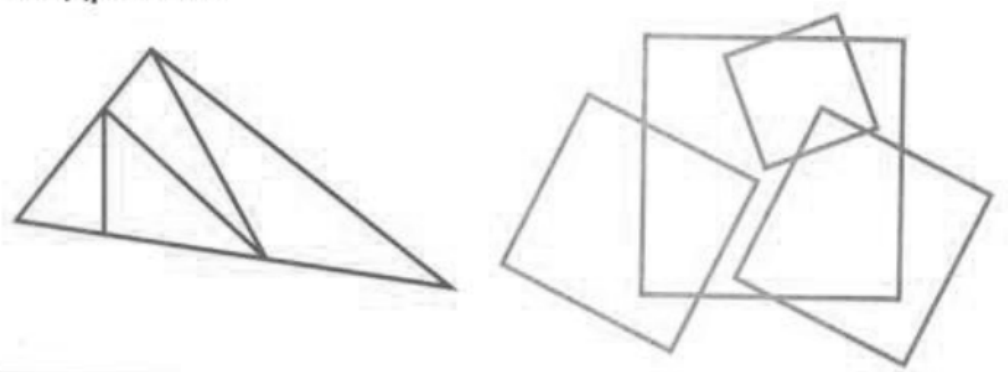

Tradução: Quantos triângulos no desenho? Quantos quadrados?

Fonte: Matemática, 2011, vol. 1, p. 55

As variadas tarefas geométricas propostas nos dois volumes do livro para o primeiro ano estimulam a generalização que, conforme o quadro 1, é parte integrante das capacidades do pensamento teórico.

A reta numérica, graduada de 0 até 10, também é introduzida visando à realização de atividades de adição e subtração. Caminhar sobre ela da esquerda para a direita significa "adicionar", caminhar da direita para a esquerda significa "subtrair" (figura 5).

Figura 5 - Reta numérica

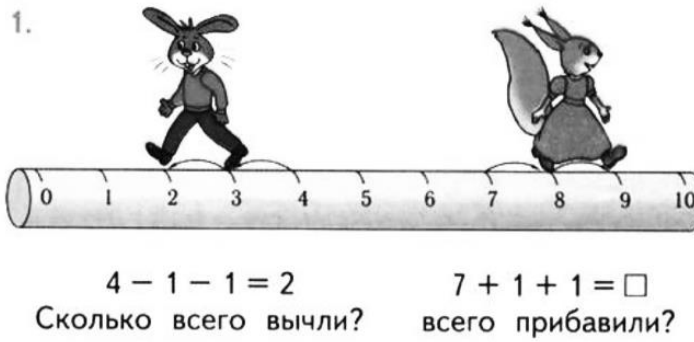

2. $5+1+1$ $5+1=\square$ $6+1=\square$

$\mathrm{cm}$

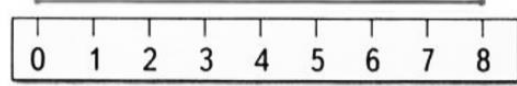

$$
\begin{array}{ll}
9-1-1 & 8-1-1 \\
9-1=\square & 8-1=\square \\
8-1=\square & 7-1=\square
\end{array}
$$

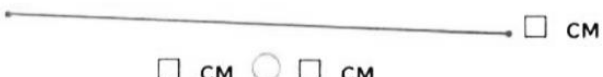

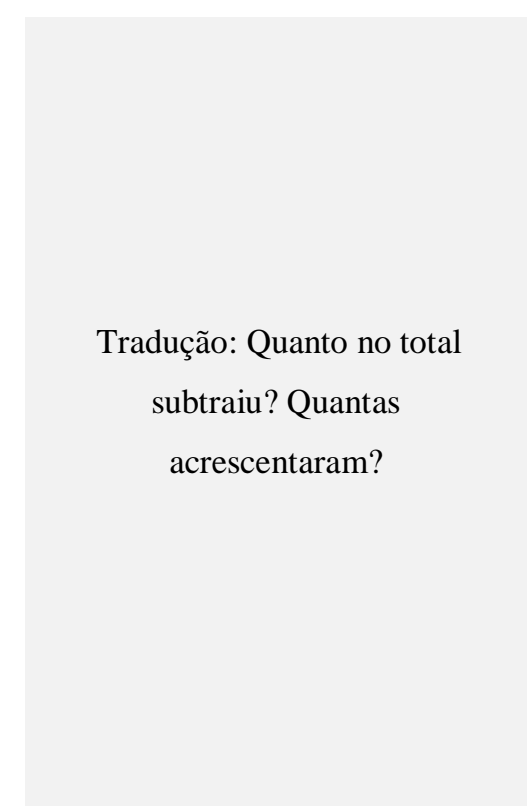

Fonte: Matemática, 2011, vol. 1, p. 82 
Na figura 5, além da reta numérica, constata-se uma atividade em que o aluno deve medir um segmento (cor rosa) e, após, outro segmento (cor verde), os quais devem ser medidos e comparados, usando a simbologia $>,<,=$. Aqui, nesse fragmento, fica clara a proposta de trabalhar com quantidades discretas e contínuas.

Notamos mais um suporte teórico na teoria de Davydov, uma vez que o processo de construção da representação da relação toma a reta numérica como um esquema.

O aluno aprenderá, no trabalho com o estudo de grandezas geométricas, a medir (com ajuda de régua) e a escrever o comprimento, usando unidades de medida estudadas - centímetro e decímetroe a correspondência entre elas; desenhar segmentos do comprimento solicitado com ajuda de régua graduada; elaborar a unidade de comprimento correspondente ao objeto medido (por exemplo, em quais unidades você poderia medir o comprimento de lápis). $\mathrm{O}$ aluno terá a possibilidade de aprender a interpretar o comprimento de segmento (do objeto), usando unidades de medida diferentes (por exemplo, 15 cm e $1 \mathrm{dm}$ e $5 \mathrm{~cm}$ ); comparar os valores, por exemplo, ordenar em função de diminuição (aumento) do comprimento: $1 \mathrm{dm}, 8 \mathrm{~cm},(8 \mathrm{~cm}, 13 \mathrm{~cm})$.

\section{Resolução de Problemas}

Na resolução de problemas, as crianças aprendem a analisar cada problema: a destacar aquilo que já é conhecido (condição) e aquilo que ainda é necessário descobrir (questão do problema) - incluindo aqueles casos em que a questão não está separada da condição (uma parte da condição está incluída na pergunta) - e a explicar a escolha da ação. As autoras usam uma forma curta de descrição do problema, desenhos esquemáticos para o problema, e anotação de sua resolução. A fim de estimular a imaginação, as autoras consideram útil propor para as crianças que inventem seus próprios problemas, usando desenhos esquemáticos (modelos) e anotações de problemas resolvidos.

Os problemas apresentados no livro didático e a metodologia deles oferecem a possibilidade de mostrar como métodos matemáticos de ação aplicam-se na prática (operações aritméticas, medições, modelagem de problemas na forma de textos etc.). Eles permitem utilizar esse conhecimento em outras disciplinas escolares, por exemplo, quando os alunos, durante o estudo, executam e anotam as mudanças de estação para estação. Já é uma preparação para que o aluno realize as próprias "pesquisas", observando, coletando informações e relatando.

Segundo Damazio (2006, p. 4), na teoria davydoviana, “o interesse é para o modo de manifestação do problema e, ao mesmo tempo, numa ação dialética, priorizar: a transformação quantidade/qualidade, a interligação todo/partes, explicação/compreensão e análise/síntese”. 
A proposta das autoras aproxima-se dessa premissa, pois o trabalho com problemas, na forma de textos, visa a que o aluno aprenda a compor, a partir de uma série de desenhos, usando para tal uma história com terminologia matemática; a diferenciar um problema na forma de texto de uma história; a completar o texto, transformando-o em um problema; a estabelecer a correspondência entre dados conhecidos do problema e os dados procurados, a interpretar o problema na forma do modelo, a selecionar e explicar as operações aritméticas para resolução do problema; a compor um problema pelo desenho, pelo esquema, pela resolução dada; a resolver problemas (de uma operação), incluindo problemas de característica prática.

É importante destacar que, já na segunda metade do primeiro ano, acontece o envolvimento do aluno com problemas a serem resolvidos em duas etapas (problemas compostos). Para isso, um trabalho preparatório precisa ser realizado: resolução de problemas encadeados, interligados por dados em comum; problemas com duas perguntas; criação de diversos problemas usando o mesmo modelo, etc.).

O livro didático contempla um amplo espectro de tarefas que exigem dos alunos as habilidades de compor novos problemas ou de transformar os que lhe são dados em outros, comparar os problemas e suas resoluções, o que contribui para o desenvolvimento dos alunos.

\section{Introdução ao pensamento algébrico}

O segundo livro do primeiro ano segue na mesma proposta de integração da aritmética com a geometria, com grande ênfase nas grandezas, tanto discretas quanto contínuas. A balança é introduzida e com ela, além da noção de equilíbrio, o conceito de quilograma. Para um valor "desconhecido" (espaço vazio) em operações do campo aditivo é sugerido o uso de uma letra. A preparação para a introdução ao ensino da álgebra começa desde o primeiro ano.

No livro de Moro et al, o conceito de desigualdade ocupa papel importante. Ele aparece também em uma representação de balança em desequilíbrio, enquanto a igualdade será representada com a balança em equilíbrio. Na figura 6 , a tarefa solicitada, para a balança à esquerda, é dizer se a massa da melancia é maior ou menor do que $5 \mathrm{~kg}$ e para a balança da direita, é calcular a massa do pacote de farinha.

Figura 6 - Tarefa da balança com alimentos 


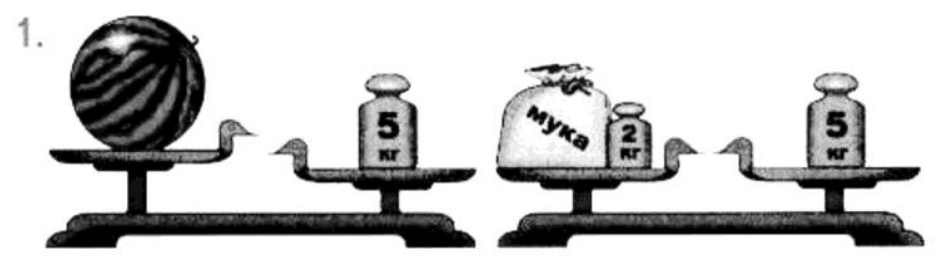

Fonte: Matemática, 2011, vol. 2, p. 34

Desde o primeiro ano, Davydov recomendava operar com objetos reais e destacar neles os parâmetros de grandezas como os pesos, volumes, comprimentos, a fim de que as crianças aprendessem a comparar coisas. Segundo ele, "a análise das mudanças das grandezas e sua anotação mediante símbolos, de menor e maior, abre o caminho à introdução de equações simples" (DAVYDOV, 1982, p. 432). Com esses exemplos temos indícios de que as autoras procuraram seguir a proposta de ensino desenvolvimental.

A fim de auxiliar o professor na realização das tarefas em sala de aula, autores como Bakhtina (2012) detalham a metodologia que o professor deve desenvolver em cada aula. Esse é o objetivo da inclusão do item a seguir.

\section{Metodologia da matemática conforme Bakhtina}

O livro Para o desenvolvimento de cada aula de matemática dos livros de Moro foi escrito por C. V. Bahktina (editora Ekzamen) e serve como uma orientação na preparação de cada aula. Segundo os editores, "as aulas contém elementos de ensino desenvolvimental, sendo material útil para professores da escola inicial" (BAKHTINA, 2012, p. 2).

A autora realça que esse material corresponde ao padrão estatal de educação (segunda geração) para a escola inicial. Na introdução do livro, ressalta que a aula está construída a partir de uma abordagem de atividade sistêmica: onde o professor é um auxiliar na aprendizagem de algo novo, e o aluno é um participante no processo de ensino de igual para igual, para quem o professor está repassando o direito de ter uma opinião própria e o direito de errar durante a análise de um novo método de resolução. (BAKHTINA, 2012, P. 7) Uma atenção especial deve ser dedicada para a formação de habilidades nas crianças para que elas descubram o tema da aula, analisando o material didático, e, também, baseando-se no que devem conhecer e no que devem aprender. Elas devem explicitar os objetivos da aula e, ao final desta, analisar quais objetivos foram alcançados e quais não, explicando a razão. Esse trabalho é necessário para a obtenção de resultados de ensino interdisciplinar ou métodos universais de ensino.

Grande atenção na aula é dedicada ao desenvolvimento de ações de auto-avaliação. Depois, da tarefa executada, o aluno recebe um padrão de execução, que deve comparar com o seu trabalho. 
Os padrões são preparados pelo professor e apresentados aos alunos em cartões, no quadro ou na forma eletrônica, mediante uso de projetor ou quadro interativo. É recomendada a utilização do mesmo procedimento quando da realização, pelos alunos, de tarefas independentemente do professor, isto é, quando o aluno não apenas está executando a tarefa, mas, também, verificando seus resultados. Os trabalhos de verificação têm por objetivo o controle sobre a aprendizagem de material quotidiano, por isso, é recomendável a sua realização ao final do tema.

\section{Conclusões}

Para psicólogos que defendem um ensino desenvolvimental é fundamental a escolha correta de conteúdos estreitamento conectados ao método de ensino desses conteúdos. Nessa obra, os conteúdos foram cuidadosamente escolhidos e direcionados à introdução de novos métodos de ensino inicial que favoreçam o desenvolvimento. Para Davydov, os fundamentos do conhecimento matemático são formados na escola inicial (primária). Essa premissa continua a valer. O primeiro ano escolar é considerado fundamental -base para a formação do educando, que engloba para o seu desenvolvimento intelectual não apenas o conhecimento matemático, mas o pensamento, a fala e a imaginação espacial. Assim, o livro didático está orientado para as ações universais cujos resultados garantem o desenvolvimento intelectual de crianças e a capacidade para a busca autônoma e aquisição dos novos conhecimentos, novos métodos de ação, que compõe a base de saber estudar.

O ensino centra-se nas atividades que visam o desenvolvimento de ações do pensamento, usando a imaginação ao inventar seus próprios problemas, executando comparações, detectando as regras de continuação, classificando pela propriedade dada, desenvolvendo a interpretação espacial, resolvendo os problemas lógicos, aplicando os conhecimentos nas condições alteradas, resolvendo os problemas propostos pelos próprios alunos e com mediação do professor.

A proposta de ensino para o primeiro ano está alicerçada na junção da aritmética com geometria, mas já com um simbolismo preparatório para a álgebra, que será trabalhada a partir do segundo ano. O material geométrico representa uma linha aberta e independente, pois, desde as primeiras lições, estuda-se em paralelo com a aritmética. Entretanto, as ligações entre aritmética e geometria se estabelecem quando possível, mas nem sempre, segundo as autoras. A execução de tarefas da natureza geométrica requer o uso de outros tipos de atividades de ensino, por exemplo, com a realização de cálculos na resolução de problemas aritméticos. Assim, o estudo em paralelo do material aritmético e geométrico também permite organizar o ensino desenvolvimental e garante uma preparação determinada para o estudo de material geométrico nas séries posteriores.

Ao professor cabe um papel importante em sala de aula, um mediador que busca uma 
interação com os alunos levantando perguntas do tipo: "Como vocês pensam?", "Analisem", "Comparem", "Terminem a explicação", "Estabeleçam conclusão". Em cada aula, é essencial realizar aquelas atividades que visam a aprendizagem e a atividade de pensamento: comparação, análise, síntese, classificação, habilidades de conduzir as discussões lógicas, generalizações possíveis no processo de estudo do material do tema.

Beltiukova, Volkova e Stepanova (2015) afirmam que o desenvolvimento de qualquer conceito, durante o estudo dos fundamentos das ciências explica-se pelo fato de que a formação de conceitos e seu uso em diversos julgamentos pressupõem um apelo para análise, comparação, síntese, generalização, abstração, concretização e outras formas de pensamento. A obra desses autoras sob a coordenação de M.I. Moro leva isso em conta e coloca como objetivo seguir as ideias de ensino desenvolvimental.

Constata-se que a abordagem de Moro et al, embora objetive um ensino desenvolvimental, não segue exatamente as propostas de Davydov, uma vez que, segundo elas, este autor propõe um ensino da matemática seguindo a ordenação: grandeza $\rightarrow$ relação $\rightarrow$ número, enquanto que a proposta das autoras segue uma sequencia diferente dos conceitos básicos: número $\rightarrow$ grandeza $\rightarrow$ relação.

O livro didático pesquisado traz indícios de que as autoras optaram por uma proposta metodológica não tão próxima daquela preconizada por Davydov, mas cujo sistema de tarefas permite que o professor as desenvolva em qualquer escola para um grande contingente de alunos. Talvez, esse seja o ponto forte da obra que é adotada há vários anos e continua a ser indicada pelo Ministério da Educação e Ciência da Federação da Rússia.

\section{Referências}

BAKHTINA, S. V. Para o desenvolvimento de cada aula de matemática dos livros de Moro, 4a. edição, Moscou: Editora Ekzamen, 2012. 319 p. serie Coletânea de metodologia de ensino.

BANTOVA, M. A.; BELTIUKOVA, G.V.; VOLKOVA, S.I.; STEPANOVA, S. V.; IGUCHEVA, I. A. Matemática - recomendações metodológicas para a primeira série: ajuda para professores das instituições gerais de ensino. Moscou: Prosvechenia, 2014.

BELTIUKOVA, VOLKOVA E STEPANOVA. Entrevista com as autoras na forma on-line. Em 20 de abril de 2015.

CHOPPIN, Alain. História dos livros e das edições didáticas: sobre o estado da arte. Estudo e Pesquisa. São Paulo, v. 30. n. 3, p. 549-566, set/dez 2004.

CIAVATTA, Maria. Estudos comparados: sua epistemologia e sua historicidade. Trab. Educ. Saúde, Rio de Janeiro, v. 7, suplemento, p. 129-151, 2009.

DAMAZIO, A. Elaboração de Conceitos Matemáticos: Abordagem Histórico-Cultural. In: 29a Reunião Anual - Associação Nacional de Pós-Graduação e Pesquisa em Educação, 2006, Caxambu. Associação Nacional de Pós-Graduação e Pesquisa em Educação. Caxambu: Anped, 2006. p. 1-19. 
DAVYDOV, V. V. Experiência de introdução do ensino de álgebra na escola inicial [Opyt vvedeniya elementov algebry v natchalcnoy chkole]. Sovetskaya Pedagogika. Moscou. 1962, n. 8. Problemas do ensino desenvolvimental - a experiência da pesquisa teórica e experimental na Psicologia. Traduzido por José Carlos Libâneo e Raquel A. M. da Madeira Freitas. Soviet

Education, Aug. 1988. VOL XXX, N 8, sob o título "Problems of Developmental Teaching. The Experience of Theoretical and Experimental Psychological Research - Excerpts".

Tipos de generalización en la enseñanza. Havana: Editorial Pueblo y Educación, 1982.

MORO, M. I. ; VOLKOVA, S. I. ; CTEPANOVA, S. V. Matemática. v. 1 (Математика). $1^{\circ}$ ano. Moscou: Proveschenia, 2011.

MORO, M.I. ; BANTOVA, M.A.; BELTIUKOVA, G.V.; VOLKOVA, S.I.; STEPANOVA, S.V.; IGUCHEVA, I.A. Matemática. v. 2 (Математика). $1^{\circ}$ ano. Moscou: Proveschenia, 2011.

ROSA, J. E. Proposições de Davýdov para o ensino de Matemática no primeiro ano escolar: inter-relações dos sistemas de significações numéricas. Tese (Doutorado em Educação). Universidade Federal do Paraná, 2012. 244f. 